\title{
INSPECTION OF MANAGEMENT ACCOUNTING STATUS AT THE ENTERPRISE
}

\author{
lana VOLKOVSKA ${ }^{1}$ \\ Simon Kuznets Kharkiv National University of Economics, Ukraine
}

\begin{abstract}
Now the heads of enterprises have understood that management accounting is important for the decision-making process. It has a particular importance when enterprises because of the specifics of their activities and optimization of taxation, consist of several business entities, for example, hotel-restaurant complexes. However, it may be a situation when there is management accounting at the enterprise but managers do not receive the necessary information. Then there is a need to check the status of management accounting. Audit of management accounting is expensive, so there is a need for cheaper ways to determine the status of management accounting. This confirms the relevance of this study. The purpose of the work is the formation of a procedure for checking the status of management accounting at the enterprise. To achieve the goal, the method of expert evaluation was used. First of all, the author selected objects for checking the status of management accounting for the understanding what to focus on. Next, the author analysed the main approaches to checking the status of management accounting and how they can be used at the enterprises of the hotel-restaurant complex. The author, on the basis of the analysis, formed possible questions about the assessment of the status of management accounting, which were evaluated by experts on the basis of the scale proposed by the author. Expert evaluations were processed and ranked by the author. The result was a questionnaire for assessment of the status of management accounting at the enterprise, with the allocation of various aspects of accounting for the consideration of different issues. The author also developed recommendations for the answers to the questionnaire and the scale for the questionnaire, which allows drawing a conclusion about the completeness of the management accounting system. It makes a conclusion that this procedure of checking the status of management accounting at the enterprise helps to understand what issues are covered by the existing management accounting system and to what extent. However, this approach does not give an answer as to whether management accounting is correctly conducted because the essence of the procedure is in checking of the system's provisioning, organization, confidentiality, and not checking of the quality of management accounting, which is the direction of further research.
\end{abstract}

Key words: management accounting, enterprise, hotel-restaurant complex, status, inspection.

JEL Classification: D89, M41, M49

\section{1. Введение}

На сегоАняшний Аень становится важным формирование учётно-аналитического обеспечения, качество которого увеличивается при наличии управленческого учёта на преАприятии. ОАнако возможны ситуации, когАа управленческий учёт так и не Ааёт ответы на отАельные вопросы или построен таким образом, что наблюдается повторение. Это приводит к тому, что необходимо проверить качество организации управленческого учёта на преАприятии, при этом желательно находить наиболее простые способы Аля проверки. Кроме того, следует отметить, что при организации управленческого учёта важно учитывать специфику деятельности предприятия, что закладывается при разработке управленческой отчётности. Свои особенности имеют и преАприя- тия гостинично-ресторанного комплекса, которые с целью оптимизации налогообложения и ведения учета обычно включают в себя несколько субъектов хозяйствования. Как слеАствие, возникают отношения межАУ центрами ответственности, подразАелениями, то есть отАельным Участком Аля контроля становится трансфертное ценообразование. Кроме того, гостинично-ресторанные компиексы явцяются частью индустрии гостеприимства, поэтому отАельной статьёй расходов становятся затраты на качество, следовательно, и сигнальные показатели контроля качества тоже надо рассчитывать и анализировать. Также значительное количество обычно составцяют административные расходы и расходы на сбыт, часть которых есть трансакционными издержками, поэтому Аля предупрежАения нецелевого использования

Corresponding author:

${ }^{1}$ Department of Accounting, Simon Kuznets Kharkiv National University of Economics.

E-mail: volkovska_yana@ukr.net 
среАств поА прикрытием преАставительских услуг руководству целесообразно также выделять отдельно такие расходы и анамизировать их Аинамику, состав и вемичину.

\section{2. Объекты проверки состояния управменческого учёта}

При осуществлении проверки, насколько полно и объективно построена система управценческого учёта, важно опреАелить его составцяющие, а именно ключевые вопросы, которые обязательно надо проверить на нацичие. Следует отметить, что объектов может быть много и мало, всё зависит от первоначальных запросов руководства и Аетализации управменческого учёта.

На мнение автора, объекты проверки состояния управленческого учёта следует разделить на 2 блока: финансовый и управленческий учёт. Это можно объяснить тем, что управленческий учёт всё равно основывается на Аанных финансового учёта, ведь нецелесообразно использовать Аругой Пиан счетов, если уже есть установленный, Аля цемей управленческого учёта Аостаточно Аобавить отдельные аналитические счета.

Так, к вопросам финансового учёта можно отнести: рабочий Пиан счетов бухгалтерского учёта, формы первичных Аокументов, организация Аокументооборота, перечень Аолжностных миц, которые имеют право подписи на первичных Аокументах, наличие установленных преАприятием перечня и состава статей калькулирования, наличие перечня установленных предприятием и состава переменных и постоянных общепроизводственных расходов, метод учёта расходов, выделение баз распределения расходов, наличие стандартов введения информации.

Также можно выдемить такие объекты управленческого учёта: нормативная база организации и ведения управленческого учёта, организация системы внутрипроизводственного учёта, контроля и отчётности, состав и формы управленческой отчётности, своевременность предоставления управленческой отчётности руководителям, которые ответственные за принятие решений, организация бюджетирования, формирование информации о расходах по обычным виАам Аеятельности, наличие центров ответственности, формирование информации про трансакционные издержки, наличие информации неучетного характера, ценообразование, анамиз прибыльности покупателей, анализ расходов на качество, показатели качества, методы ценообразования, наличие программного обеспечения Аля ведения управленческого учёта, наличие сотрудника, отАела за ведение управленческого учёта, регламент сбора, обработки и хранения информации, наличие сбалансированной системы показателей, сигнальных показателей Аля контромя и систем оценивания и контроля отклонений от плана.
Таким образом, сформирован перечень объектов проверки состояния системы управленческого учета и выделены специфические объекты Аля гостинично-ресторанного комплекса, а именно формирование информации о трансакционных издержках, анализ прибыльности покупатемей, анамиз затрат на качество, показатели качества, метод трансфертного ценообразования. Аамее цемесообразно проанализировать митературу на суть проверок управленческого учёта, этапы и основные вопросы.

\section{3. Подходы к Проверке состояния управленческого учёта}

Аля обоснования объектов управленческого учета автором были проанализированы рекоменАации разАичных ученых и экономистов-практиков по проверке состояния управленческого учета, что преАставлено в табл. 1. Следует заметить, что не все объекты, рассмотренные ранее, можно встретить в анализе подходов, т.к. учёными не учитывается специфика предприятий гостинично-ресторанного комплекса, на которой Аелается акцент в Аанной работе.

Как можно увидеть, важнейшими объектами явмяются нормативная база ведения управленческого учета, формы управленческого учета и наличие системы показателей Аля анализа, и это могично. Так,

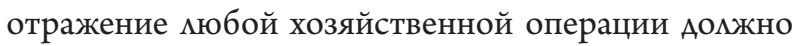
быть обоснованным, а Аля этого все возможные действия и исполнители Аолжны закрепляться в том или ином документе. Если не будут разработаны формы отчетности, то гае фиксировать необходимые Аополнительные Аанные, рассчитывать показатели, освещать их анализ и прописывать выводы и предложения по Аальнейшему развитию предприятия. При этом, как отмечает Тютюнник В., важно не просто проверять наличие форм отчетности, а устанавливать уровень их сопоставимости, Аостоверность, при этом отчеты Аолжны быть читабельными не только

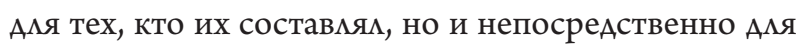
пользователей (2013).

Кроме того, CIMA и AICPA Аля внутреннего контроля отАельно выАемяют процеАуры управления рисками Аля созАания и сохранения стоимости бизнеса (2015), это явмяется Аействительно важным, оАнако реАко, когАа провоАится на преАПриятии. Обычно большинство руководителей Аелают собственные преАположения относительно рискованности той или иной операции на основании собственной интуиции и мишь некоторых отдельных фактов. Это приводит или к возникновению мишних затрат, или к потере возможных Аоходов, то есть к уменьшению экономической прибыли. Также Волошин А. А., Аоктев А. В. Аелают акцент на стратегическом управменческом учете (2010), поэтому оАним из объектов оценки эффективности системы управменческого 
Таблица 1

Анализ подходов к проверке состояния управменческого учёта

\begin{tabular}{|c|c|c|c|c|c|c|c|}
\hline Объекты & $\begin{array}{l}\dot{4} \\
\dot{4} \widehat{n} \\
\text { 总 } \\
\text { 总 } \\
0\end{array}$ & 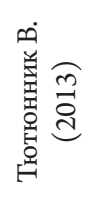 & 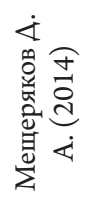 & 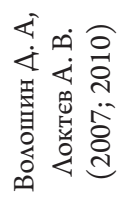 & 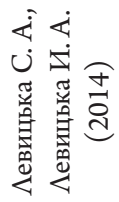 & 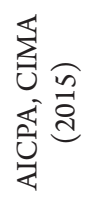 & 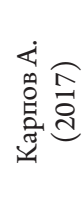 \\
\hline $\begin{array}{l}\text { Нормативная база системы управленческого } \\
\text { учёта на преАприятии }\end{array}$ & + & + & + & + & + & + & + \\
\hline Рабочий план счетов бухгалтерского учёта & & + & + & & & & \\
\hline $\begin{array}{l}\text { Наличие распредемения функций межАу } \\
\text { подраздемениями и сотрудниками, } \\
\text { взаимодействия межАу ними, соответствия } \\
\text { организационной структуре }\end{array}$ & + & & & & & + & \\
\hline $\begin{array}{l}\text { Организация бюАжетирования на } \\
\text { преАприятии }\end{array}$ & & & + & + & + & + & \\
\hline $\begin{array}{l}\text { Наличие системы оценивания и контромя } \\
\text { откмонений от плана }\end{array}$ & & & & + & & + & \\
\hline $\begin{array}{l}\text { Система управмения и организационная } \\
\text { структура }\end{array}$ & & & + & + & & + & \\
\hline $\begin{array}{l}\text { Направления деятемьности и центры } \\
\text { ответственности }\end{array}$ & & & + & + & & & \\
\hline Организация документооборота & & + & + & + & + & + & + \\
\hline Принципы обработки учётной информации & & + & & + & & & + \\
\hline Формы управленческой отчётности & & + & + & + & + & + & + \\
\hline $\begin{array}{l}\text { Оперативность получения Аанных } \\
\text { соответствующими специалистами }\end{array}$ & & + & & & & & \\
\hline $\begin{array}{l}\text { Наличие стратегического плана развития } \\
\text { системы управленческого учёта }\end{array}$ & & & & + & & & \\
\hline Наличие системы показателей дмя анализа & + & + & & & & & \\
\hline Выявмение перспектив деятельности & + & & & & & & \\
\hline Наличие процеАур управления рисками & & & & & & + & \\
\hline
\end{tabular}

учета явцяется наличие стратегического плана развития системы управленческого учета, однако, по мнению автора, это не совсем целесообразно, веАь система управленческого учета полностью зависит от потребностей пользоватемей информации, поэтому если будут вноситься изменения в стратегический план развития непосредственно предприятия, то автоматически будет возникать потребность в АоПолнительных Аанных, которые будут опреАемяться, и Аля их получения уже будет формироваться новый участок учета, однако отдельно выделять этот Аокумент станет мишь Аополнительными затратами. И важным является контроль таких вопросов, как осуществмение мероприятий по проведению бенчмаркинга и соотношение выгод и затрат на функционирование системы управленческого учета, веАь, с одной стороны, нужно постоянно мониторить бизнес-среду, в которой функционирует преАприятие, с Аругой стороны, возможна ситуация, когда существующая система управленческого учета является слишком Аорогой и не Аобавляет выгод по сравнению с затраченными на нее среАствами.

Необходимо добавить, что Аевицкая С. А. и Аевицкая И. А. также преАлагают тесты внутреннего кон- троля формирования (калькуляции) затрат, где выдемяют такие блоки, как условия (все ми услуги подкреплены соответствующими заключенными Аоговорами, подписаны ми первичные Аокументы, проверяется ки правильность отнесения сырья и материалов на расходы, понесенные при выполнении ремонтов и т.п.), реальность и полнота (сопоставляются ми данные в приходных ордерах на сырье и материалы по их фактической стоимости согласно условиям Аоговоров, своевременно ки поступают акты оказанных услуг от подрядных организаций и т.п.), возможности (все ми условия Аоговоров на выполнение ремонтных работ подрядными организациями согласовано компетентными Аолжностными кицами и т.А.), компетентность (проведен ми инструктаж работников, осуществцяющих размичные учетные операции в автоматизированной системе учета) и учет (сопоставмяются ми Аанные первичных документов с Аанными ГАавной книги, показателями форм отчетности) (2014). Такие тесты можно разработать Аля размичных подраздемений (центров ответственности) гостинично-ресторанного комплекса с сохранением и расширением этих раздемов. 


\section{4. ПровеАение анкетирования}

Итак, в Аальнейшем Амя проверки состояния управменческого учета необходимо разработать анкету по оценке системы управленческого учета, которую будут заполнять уже непосредственно заказчики проверки, но Аля подтвержАения того, что анкета Аолжна включать именно такие вопросы, целесообразно привлечь экспертов, таким образом, необходимо определить минимальное количество экспертов и их состав Аля проведения опроса, какие участки слеАует проверять Аля установления состояния системы управленческого учета, а какие - нет. Как отмечает Рупоносов В. А., Аля определения количества экспертов можно преАложить зависимость межАу наличием объектов или эмементов, оцениваемых по следующей формуле (2015):

$$
m=\sqrt{ } n \text {, }
$$

гАе $m$ - необходимое количество экспертов, чел.;

$n$ - количество объектов, которые оцениваются, шт.

Как указано ранее, всего Амя проверки есть 30 объектов управленческого учета, следовательно, Аля заполнения анкеты необходимо 6 экспертов. При выборе экспертов была учтена специфика управленческого учета и Аеятельности преАприятий гостинично-ресторанного комплекса. Эти эксперты на каждый вопрос ставими оценку от 0 Ао 5 бамлов. Ниже преАставлена шкала оценивания целесообразности вкцючения вопросов в анкету проверки состояния управленческого учёта на преАприятии:

0 - вопрос не касается управленческого учёта;

1 - этот элемент (участок) управленческого учёта не важен Амя преАприятий, ими такая информация уже формируется в финансовом учёте в соответствии с национальными стандартами; содержание вопроса Аублируется с Аругими вопросами;

2 - Аанный вопрос целесообразно заАавать в инАивидуальных ситуациях, однако в универсальную систему управленческого учёта на преАприятии этот объект можно не включать; Аанный вопрос можно рассматривать, однако он скорее явмяется принципом ведения управленческого учёта, который целесообразно выполнять, а не обязательным элементом, без которого система не будет работать эффективно;

3 - вопрос явцяется важным, оАнако Аля экономии средств его можно исключить; преАприятие ведёт такой учёт только по желанию, отсутствие этого эмемента не повцияет на качество системы управценческого учёта;

4 - вопрос целесообразно включить в анкету, однако есть сомнения относительно объективности ответа на него;

5 - отмеченные элементы обязательно Аолжны присутствовать в системе управленческого учёта.

Респондентам было преАложено Аать оценку кажАому вопросу о состоянии управленческого учета, тем самым проранжировать их путем присвоения бамлов (бальный метоА). Автором выдемены разАелы в анкете опроса экспертов, это сАелано Аля понимания, Аля чего задано вопросы. Обработка результатов осуществцялась на основе использования метода непосредственного оценивания (бального метода), т.е. упорядочения исследуемых объектов в зависимости от важности путем приписывания бамлов каждому из них. При этом наиболее важный объект насчитывает наибольшее количество бамлов по принятой шкале, которая отмечена выше. Соответственно, по каждому вопросу были посчитаны общая сумма бамлов, весомость вопроса и установмен ранг, по которому Аалее и отбирались вопросы в анкету. ОАнако Аля понимания, насколько совпадами мнения экспертов при ранжировании вопросов, необходимо рассчитать коэффициент согласованности (коэффициент конкордации КенАамма):

$$
\mathrm{W}=\frac{12 \sum_{i=1}^{n} D_{i}^{2}}{m^{2}\left(n^{3}-n\right)},
$$

где $W$ - коэффициент конкордации;

$n$ - количество оцениваемых объектов;

$m$ - количество экспертов, которые принимали участие в опросе;

$D$ - Аисперсия отклонения от среднего (Рупоносов, 2015).

Таким образом, при проведении расчёта степени согласованности экспертов было определено, что коэффициент конкордации равен 0,88 , что свидетельствует о высокой степени согласованности. Аалее была оценена значимость согласования Пирсона и установлено, что 0,88 - величина не случайная, значит, полученные результаты имеют смысл и могут использоваться в исследованиях.

\section{5. Формирование анкеты оценивания состояния управменческого учёта}

По мнению автора, слишком много вопросов в анкете, которую будут заполнять заказчики, приведёт к тому, что её будут заполнять частично необъективно или невнимательно, потому что из проранжированных вопросов предлагается включать в анкеты первые 55 по важности. Это объясняется тем, что самих объектов управленческого учёта в Аанной работе выделено 30 штук, поэтому если вкАючить в анкету мало вопросов, то не удастся оценить в полной мере систему управленческого учёта, однако включение всех вопросов приведёт к неточности ответов, как было отмечено ранее. Таким образом, на основании экспертного опроса сформировано следующую анкету Аля тестирования системы управленческого учёта на преАприятии, что преАставлено в табл. 2 .

Аля ответа на преАставценные вопросы также будет предоставлена шкала оценивания от 1 до 5. Следует отметить, что проходя тестирование, респонденты Аолжны отвечать, исходя из того, есть это или нет, а 
не из преАположения, что в этой информации субъект хозяйствования не нужАается. Итак, рекоменАации по оцениванию ответов на анкету проверки состояния управленческого учёта на преАприятии смедующие:

1 - на Аанный вопрос можно ответить «нет», т.е. указанное в вопросе отсутствует в существующей системе управленческого учёта;

2 - присутствуют только отдельные Аокументы или только в некоторых случаях такая система используется;
3 - база Аля использования Аанного элемента есть, но не используется;

4 - Аанный эмемент присутствует или используется, но есть аспекты, которые необходимо усовершенствовать;

5 - на Аанный вопрос можно ответить «Аа», т.е. такое полностью разработано, присутствует и используется в системе управленческого учёта.

Необходимо отметить, что на отАельные вопросы можно ответить только мибо «Аа», мибо «нет», это только обцегчает оценки и увеличивает его объ-

Таблица 2

Тестирование системы управценческого учёта на преАприятии

\begin{tabular}{|c|c|c|c|}
\hline № & Вопросы & Обоснование & Оценка \\
\hline 1 & 2 & 3 & 4 \\
\hline \multicolumn{4}{|c|}{ 1. Методическое обеспечение } \\
\hline 1.1 & $\begin{array}{l}\text { Присутствуют ми нормативные Аокументы, которые } \\
\text { регулируют организацию и ведение управленческого учёта? }\end{array}$ & - & $1-5$ \\
\hline 1.2 & $\begin{array}{l}\text { Есть Аи положение про организационную структуру на } \\
\text { предприятии? }\end{array}$ & - & $1-5$ \\
\hline 1.3 & $\begin{array}{l}\text { УтвержАён ми рабочий План счетов Аля цемей управленческого } \\
\text { учёта? }\end{array}$ & П. 5 ст. 8 Закона №996-XIV & $1-5$ \\
\hline 1.4 & Установлены ки состав и перечень статей калькулирования? & $\begin{array}{c}\text { Приказ Министерства финансов } \\
\text { Украины от 27.06.2013 № 635, П(С)БУ } \\
16\end{array}$ & $1-5$ \\
\hline 1.5 & $\begin{array}{l}\text { УтвержАён ли перечень и состав переменных и постоянных } \\
\text { общепроизводственных расходов? }\end{array}$ & $\begin{array}{c}\text { Приказ Министерства финансов } \\
\text { Украины от 27.06.2013 № } 635\end{array}$ & $1-5$ \\
\hline 1.6 & $\begin{array}{l}\text { УтвержАён Аи метоА учёта расходов и поАходы к определению } \\
\text { себестоимости? }\end{array}$ & П(С)БУ 16 & $1-5$ \\
\hline 1.7 & Организована ми система бюджетирования на предприятии? & - & $1-5$ \\
\hline 1.9 & $\begin{array}{l}\text { Есть ми методики оценки эффективности Аеятельности } \\
\text { центров ответственности и их качества? }\end{array}$ & - & $1-5$ \\
\hline 1.10 & $\begin{array}{l}\text { Установлен ли регламент сбора, обработки и сохранения } \\
\text { необходимой информации? }\end{array}$ & П. 5 ст. 8 Закона №996-XIV & $1-5$ \\
\hline 1.11 & $\begin{array}{l}\text { Установлены ми масштабы количественные, часовые, } \\
\text { качественные рамки системы управленческого учёта? }\end{array}$ & П. 5 ст. 8 Закона №996-XIV & $1-5$ \\
\hline \multicolumn{4}{|c|}{ 2. Условия } \\
\hline 2.1 & Все ми поАразделения веАут бухгалтерский учёт? & П. 5 ст. 8 Закона №996-XIV & $1-5$ \\
\hline 2.2 & Выделены ки центры ответственности? & - & $1-5$ \\
\hline 2.4 & $\begin{array}{l}\text { Проверяется ми правильность отнесения сырья и материалов, } \\
\text { услуг к расходам? }\end{array}$ & П(С)БУ 16 & $1-5$ \\
\hline 2.5 & $\begin{array}{l}\text { Все ми ускуги подкреплены соответствующими подписанными } \\
\text { договорами? }\end{array}$ & - & $1-5$ \\
\hline \multicolumn{4}{|c|}{ 3. Реальность и полнота } \\
\hline 3.1 & Все ми операции зафиксированы в документах? & Ст. 9 Закона №996-XIV & $1-5$ \\
\hline 3.2 & $\begin{array}{l}\text { Есть Аи подтвержАение целесообразности возникновения всех } \\
\text { трансакционных затрат? }\end{array}$ & 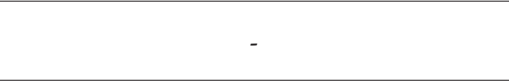 & $1-5$ \\
\hline 3.3 & $\begin{array}{l}\text { Сопоставцяются ми Аанные в приходных ордерах на сырьё } \\
\text { и материалы, в актах приёмки-переАачи работ, услуг с их } \\
\text { фактической стоимостью по условиям договора? }\end{array}$ & - & $1-5$ \\
\hline 3.4 & $\begin{array}{l}\text { Своевременно ми дохоАят документы от сторонних } \\
\text { организаций? }\end{array}$ & Ст. 9 Закона №996-XIV & $1-5$ \\
\hline \multicolumn{4}{|c|}{ 4. Полномочия } \\
\hline 4.1 & $\begin{array}{l}\text { УтвержАён ми перечень Аолжностей миц, которые имеют право } \\
\text { подписи на первичных документах? }\end{array}$ & - & $1-5$ \\
\hline 4.2 & $\begin{array}{l}\text { УтвержАены ми ответственные по кажАому центру } \\
\text { ответственности? }\end{array}$ & - & $1-5$ \\
\hline
\end{tabular}


Vol. 3, No. 4, 2017

Окончание таблицы 2

\begin{tabular}{|c|c|c|c|}
\hline 1 & 2 & 3 & 4 \\
\hline 4.3 & $\begin{array}{l}\text { Все Аи условия договоров на выполнение работ сторонними } \\
\text { организациями согласованы компетентными должностными } \\
\text { мицами? }\end{array}$ & - & $1-5$ \\
\hline 4.5 & $\begin{array}{l}\text { СозАаны ми условия Амя разграничения ответственности } \\
\text { относительно достижения цели межАу поАраздемениями? }\end{array}$ & - & $1-5$ \\
\hline \multicolumn{4}{|c|}{ 5. Компетентность } \\
\hline 5.1 & УтвержАён ли состав учётных сотруАников и их полномочия? & - & $1-5$ \\
\hline 5.2 & Проходят ли обучение учётные сотрудники? & - & $1-5$ \\
\hline \multicolumn{4}{|c|}{ 6. Учёт } \\
\hline 6.1 & Утверждены ли формы первичных документов? & $\begin{array}{c}\text { Ст. } 9 \text { Закона №996-XIV, Приказ } \\
\text { Министерства финансов Украины от } \\
24.05 .1995 \text { № } 88\end{array}$ & $1-5$ \\
\hline 6.2 & Разработан ми график документооборота? & & $1-5$ \\
\hline 6.3 & Разработаны ми формы управленческой отчётности? & П. 5 ст. 8 Закона №996-XIV & $1-5$ \\
\hline 6.4 & УтвержАён ли состав управленческой отчётности? & & $1-5$ \\
\hline 6.5 & $\begin{array}{l}\text { Утверждены ли формы бюАжетов, которые составмяются на } \\
\text { разных уровнях управления? }\end{array}$ & - & $1-5$ \\
\hline 6.6 & Утверждена ми периодичность составления бюАжетов? & - & $1-5$ \\
\hline 6.8 & Формируется ми информация неучетного характера? & - & $1-5$ \\
\hline 6.9 & Выделены ми места возникновения затрат? & - & $1-5$ \\
\hline 6.10 & Утверждена ми база распределения расходов? & П(С)БУ 16 & $1-5$ \\
\hline 6.11 & Осуществляется ми трансфертное ценообразование? & - & $1-5$ \\
\hline 6.12 & $\begin{array}{l}\text { Сопоставмяются ми Аанные первичных документов и } \\
\text { управленческой отчётности? }\end{array}$ & - & $1-5$ \\
\hline 6.13 & УтвержАены ми станАарты ведения отчётности? & - & $1-5$ \\
\hline 6.16 & $\begin{array}{l}\text { Формируется ми информация относительно возникновения } \\
\text { трансакционных затрат? }\end{array}$ & - & $1-5$ \\
\hline \multicolumn{4}{|c|}{ 7. Анализ } \\
\hline 7.1 & Проводится ми бенчмаркинг? & - & $1-5$ \\
\hline 7.2 & Утверждены ми методы ценообразования? & - & $1-5$ \\
\hline 7.3 & Проводится ми анализ прибыльности покупателей? & - & $1-5$ \\
\hline 7.4 & Формируются и анализируются ли расходы на качество? & - & $1-5$ \\
\hline 7.5 & Используется ми сбалансированная система показателей? & - & $1-5$ \\
\hline 7.6 & $\begin{array}{l}\text { Выдемяются ми сигнальные показатели деятельности по } \\
\text { центрам ответственности? }\end{array}$ & - & $1-5$ \\
\hline 7.8 & $\begin{array}{l}\text { Анализируются ми отклонения от запланированных } \\
\text { показателей? }\end{array}$ & - & $1-5$ \\
\hline 7.9 & Анализируется ми эффективность деятельности преАприятия? & - & $1-5$ \\
\hline 7.10 & Формулируются ли тенденции развития преАприятия? & - & $1-5$ \\
\hline 7.11 & $\begin{array}{l}\text { Выделяются ми резервы повышения эффективности } \\
\text { Аеятельности? }\end{array}$ & - & $1-5$ \\
\hline 7.12 & $\begin{array}{l}\text { Анализируются ми риски преАприятия при осуществлении той } \\
\text { или иной деятельности? }\end{array}$ & - & $1-5$ \\
\hline \multicolumn{4}{|c|}{ 8. Конфиденциальность } \\
\hline 8.1 & $\begin{array}{l}\text { Проинструктурированы ки сотрудники относительно } \\
\text { конфиденциальности информации? }\end{array}$ & - & $1-5$ \\
\hline 8.2 & ПодАерживается ли конфиденциальность информации? & - & $1-5$ \\
\hline \multicolumn{4}{|c|}{ 9. Эффективность } \\
\hline 9.1 & $\begin{array}{l}\text { Своевременно ми предоставмяется управленческая отчётность } \\
\text { руководителям, которые ответственные за принятие решений? }\end{array}$ & - & $1-5$ \\
\hline 9.2 & $\begin{array}{l}\text { Сопоставмяются ми расходы на организацию управленческого } \\
\text { учёта с выгодами от её наличия? }\end{array}$ & - & $1-5$ \\
\hline 9.5 & $\begin{array}{l}\text { УАовлетворяет ми система управленческого учёта нужАы } \\
\text { пользоватемей? }\end{array}$ & - & $1-5$ \\
\hline 9.6 & $\begin{array}{l}\text { Есть ми потребность ими целесообразность во внесение } \\
\text { изменений в существующую систему управленческого учёта? }\end{array}$ & - & $1-5$ \\
\hline 9.7 & Есть ми параметры качества системы управленческого учёта? & - & $1-5$ \\
\hline
\end{tabular}


ективность. Руководство самостоятельно решает, кому отвечать на преАставленную анкету, однако целесообразно, чтобы это Аелал руководитель отАела по ведению управленческого учёта, то есть человек, который понимает, каким образом организован учет на предприятии. После этого оцениваются результаты тестирования путем расчета среАнего значения. По мнению автора, рассчитывать итоговый интеграцьный показатель нецелесообразно, так как возможна ситуация, когАа нескольких участков может вообще не быть, а на показателе это почти не отразится за счет максимацьно организованного учета на Аругих участках. При расчете же среАнего значения будет сразу понятно, что чего-то не хватает.

Автором разработана такая шкала оценивания результатов тестирования проверки состояния управленческого учёта на предприятии:

4,5-5,0 - система управленческого учёта на Аостаточном уровне и требует кишь некоторых усовершенствований ими изменений, которые связаны с запросами руководства;

4,0-4,99 - система управленческого учёта может использоваться в таком состоянии, оАнако нужАается в усовершенствованиях и дополнениях Аля укучшения информационного обеспечения, если недостающая информация нужна Аля пользователей, в ином случае систему продолжают использовать без изменений;

3,0-3,99 - система управленческого учёта не охватывает все вопросы, поэтому всё зависит от запросов руководства, если их неАостающая информация не интересует, то можно оставить всё, как есть, в ином случае вносить коррективы в существующую систему;

2,0-2,99 - организованы только отАельные участки управленческого учёта, что является неАостаточным Аля формирования информационной базы Аля принятия управленческих решений, много вопросов не охвачено совсем;

1,0-1,99 - присутствуют только отдельные аспекты управленческого учёта, однако сама система выгод не предоставляет; система управленческого учёта отсутствует на преАприятии.

\section{6. ВЫводы}

Таким образом, проведение такого анкетирования Аает понять, на каком уровне организована система управленческого учета, и что надо отдельные участки совершенствовать и Аобавмять. Ее целесообразно использовать на предприятиях, которые уже работают некоторое время, т.к. Аолжна быть база Амя проверки. Также следует отметить, что такую анкету со шкалами оценивания можно использовать не только на преАприятиях гостинично-ресторанного комплекса, а и на Аругих, т.к. расходы на качество, трансакционные расходы и т.п. касаются многих преАприятий. ОАнако такой способ проверки не Ааёт ответов, правильно ми веАётся учёт, т.к. суть процеАуры в проверке, всё $и$ есть в наличии и насколько скоординировано, чтобы удовлетворять информационные потребности и не допускать утечки информации, при этом не анализируется качество ведения управленческого учёта, что явмяется направлением Аальнейших исследований.

\section{References:}

Olijny`k, O. O. (2015). Management audit: theoretic aspects and features of development in Ukraine. Bulletin of the National University of Water Management and Nature Management, 1: 104-110.

Tyutyunny`k, V. (2013). Management accounting as an important element of activity. Independent auditor, 3: 46-48.

Mescheryakov, D. A. (2014). Management audit: mechanisms of organization and optimization. Theory and practice of social development, 16: 94-97.

Voloshin, D. A. \& Loktev, A. V. (2010). Improvement of management accounting system. doi http://www.cfin.ru/ management/controlling/mas_improvement.shtml

Voloshin, D. A. (2007). Internal audit of management accounting at the enterprise. Management accounting and analysis, 19: 52-57.

Levy'cz'ka, S. O. \& Levy'cz'ka, I. O. (2014). Management audit as a tool of optimization of the costs of energy supply companies. Scientific-practical edition «Independent auditor», 9: 29-38.

Global management accounting principles by AICPA and CIMA (2015) doi: http://www.cimaglobal.com/ Documents/Employer\%20docs/web\%20pages\%202016/global-management-accounting-principles.pdf

Karpov, A. (2017) Analysis (audit) of management accounting system and statement doi: http://bud-tech.ru/ ma_analyze.html

Ruponosov, V. L. (2015). Methods for determining the number of experts. Bulletin of IrGTU, 3: $286-292$. 


\section{Яна ВОЛКОВСКАЯ}

\section{ПРОВЕРКА СОСТОЯНИЯ УПРАВЛЕНЧЕСКОГО УЧЁТА НА ПРЕДПРИЯТИИ}

Аннотация. Сейчас руководители предприятий поняли, что управленческий учёт имеет важное значение для принятия управленческий решений. Особое значение он имеет того, когда предприятия из-за специфики деятельности и оптимизации налогообложения состоят из нескольких субъектов хозяйствования, например, гостинично-ресторанные комплексы. Однако может быть ситуация, когда управленческий учёт на предприятии есть, но нужной информации руководство не получает или же в недостаточном количестве. Тогда возникает необходимость проверки состояния управленческого учёта. Аудит управленческого учёта требует больших затрат и времени, поэтому возникает необходимость в более дешёвых способах определения состояния управленческого учёта. Это подтверждает актуальность данного исследования. Целью работы является формирование процедуры проверки состояния управленческого учёта на предприятии. Для достижения цели был использован метод экспертных оценок. В первую очередь, автором были выделены объекты проверки состояния управленческого учёта для понимания, на чём именно акцентировать внимание, при этом объекты были разделены по отношению к финансовому и управленческому учёту, т.к. управленческий учёт включает в себя также и данные финансового учёта, которые в том числе важны для управления. Далее автор проанализировал основные подходы к проверке состояния управленческого учёта и как их можно использовать на предприятиях гостинично-ресторанного комплекса путём выделения основных пунктов и их сравнения. Таким образом, автор на основе проведенного анализа сформировал возможные вопросы по оценке состояния управленческого учёта, которые оценивались экспертами на основании шкалы, предложенной автором. Оценки экспертов были обработаны автором и проранжированы. Данная процедура осуществлялась бальным методом. Результатом стала анкета оценки состояния управленческого учёта на предприятии с выделением различных аспектов учёта для учёта разных вопросов. Также автором разработаны рекомендации по ответам на анкету и шкала оценивания анкеты, которая позволяет сделать вывод относительно полноты системы управленческого учёта. Следует отметить, что хоть анкета и разрабатывалась на примере предприятий гостинично-ресторанного комплекса, но носит универсальный характер и может использоваться и в других отраслях, а также при желании дополняться вопросами, т.к. в дальнейшем для оценивания берётся среднее значение. Это увеличивает практическую ценность предложенного анкетирования. Сделан вывод, что данная процедура проверки состояния управленческого учёта на предприятии помогает понять, какие вопросы охватывает существующая система управленческого учёта и в какой степени. Однако данный подход не даёт ответов, правильно ли ведётся учёт, т.к. суть процедуры в проверки наполняемости системы, её организованности, конфиденциальности, а не проверки качества ведения управленческого учёта, что является направлением дальнейших исследований. 